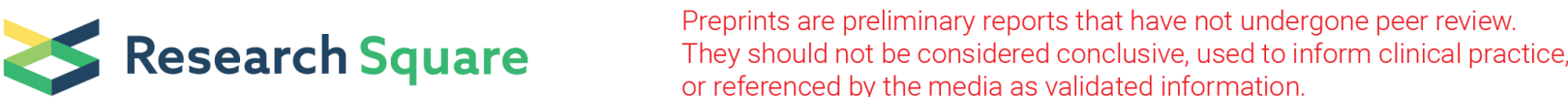

\section{Computed Tomography Determined Sarcopenia is a Significant Predictor of Poor Clinical Outcome in Gastric Cancer}

Yasar YILDIZ ( $\sim$ dryasar2706@yahoo.co.uk)

İzmir Kâtip Çelebi Üniversitesi Tip Fakültesi: Izmir Katip Celebi Universitesi Tip Fakultesi

https://orcid.org/0000-0002-2912-3835

sebnem karasu

Izmir Katip Celebi Universitesi Tip Fakultesi

utku Oflazoglu

Izmir Katip Celebi Universitesi Tip Fakultesi

Kenan cetinoglu

Izmir Katip Celebi Universitesi Tip Fakultesi

Burcin Dalkılınc

Izmir Katip Celebi Universitesi Tip Fakultesi

Yüksel Kucukzeybek

Izmir Katip Celebi Universitesi Tip Fakultesi

Ahmet Alacacioglu

Izmir Katip Celebi Universitesi Tip Fakultesi

Sinan Unal

Izmir Katip Celebi Universitesi Tip Fakultesi

Zeynep Guc

Izmir Katip Celebi Universitesi Tip Fakultesi

betül kücükzeybek

Izmir Katip Celebi Universitesi Tip Fakultesi

tarık salman

Izmir Katip Celebi Universitesi Tip Fakultesi

\section{Research Article}

Keywords: computed tomography, gastric cancer, sarcopenia, survival

Posted Date: February 1st, 2022

DOI: https://doi.org/10.21203/rs.3.rs-1200392/v1 
License: (c) (i) This work is licensed under a Creative Commons Attribution 4.0 International License. Read Full License 


\section{Abstract}

\section{Background}

Sarcopenia is defined as a progressive and extensive loss of muscle mass and function. This study aimed to investigate the impact of sarcopenia and body composition on survival outcomes in patients with newly diagnosed gastric carcinoma (GC).

\section{Materials and methods}

Skeletal muscle area was measured at the level of the third lumbar vertebra (L3) using baseline CT images in patients with GC. Sarcopenia was defined as a L3 Skeletal muscle index (SMI) of $<41.6$ $\mathrm{cm}^{2} / \mathrm{m}^{2}$ for men and $<32 \mathrm{~cm}^{2} / \mathrm{m}^{2}$ for women using van der Werf's cutoffs. The disease free survival (DFS), overall survival (OS) and clinical characteristics of patients with and without sarcopenia were compared.

\section{Results}

A total of 226 patients were included. The median age of patients was 62 years (range 18-85) and 154 patients $(68.1 \%)$ were men. Of the patients $37.6 \%$ were metastatic. Sarcopenia was present in 75 patients (33.2\%) and was at significantly higher frequencies in men, metastatic disease, lower body mass index $(\mathrm{BMI}<30)$, and higher ages ( $\geq 65$ years) (respectively; all $p<0.05$ ). The median DFS was 27 months $(95 \% \mathrm{Cl}, 1.5$ to 52.4$)$ in patients with sarcopenia and non-appliceable in patients without sarcopenia in patients undergoing curative surgery for gastric cancer $(\mathrm{p}=0.041)$. The median OS was 10 months $(95 \% \mathrm{Cl}, 7.730$ to 12.270$)$ in patients with sarcopenia and 29 months $(95 \% \mathrm{Cl}, 21.307$ to 36.693$)$ in patients without sarcopenia $(p<0.0001)$. In the multivariate Cox regression model, sarcopenia (with or without) $(B=1.101 ; p<0.0001)$, stage (1-3 vs 4$)(B=1.087 ; p=0.016)$ and surgical resection margin (R0 vs R1-2) $(B=1.029 ; p<0.0001)$ were statistically significant predictors for OS.

\section{Conclusion}

Sarcopenia is an independent clinical predictor for poor prognosis in patients with GC. Early diagnosis and screening of sarcopenia may have a positive effect on survival outcomes.

\section{Introduction}

Gastric cancer is the fifth most common cancer and third leading cause of cancer-related deaths in the world ${ }^{1}$. Due to the aggresiveness of disease and the lack of effective screening methods, the majority of patients are diagnosed at advanced stage, and the 5 -year overall survival rate is generally less than $20 \%{ }^{2}$. There is a number of clinical indicators which are related to prognosis in GC. Tumor stage is the most important predictor of the long-term prognosis ${ }^{3}$. In addition, studies have demonstrated well-known clinical and pathological features such as the presence of lymph node involvement, lymphovascular 
invasion, perineural invasion, D2 plus lymphadenectomy, RO resection margin and performance status of the patient ${ }^{3-5}$. Despite that, there is still a need for the detection of potentially modifiable prognostic factors. Recently, sarcopenia has been identified as a negative prognostic factor which has an effect on morbidity and mortality in many cancer types ${ }^{6-8}$.

Sarcopenia was firstly described in the 1980 s as an age-related decrease in lean body mass affecting nutritional status, mobility and independence ${ }^{9}$. The definition of sarcopenia has been since developed. Sarcopenia is a syndrome defined as a progressive and generalised skeletal muscle disorder that is related to increased probability of adverse outcomes including physical deformity, falls, fractures, treatment complications and mortality by The European Working Group on Sarcopenıa in Older People 2 (EWGSOP2) and European Society of Parenteral and Enteral Nutrition (ESPEN) ${ }^{10}$. Primary causes of sarcopenia are nutritional factors and age related inactivity. Cancer-related diseases are the secondary cause. The risk of sarcopenia is higher in untreated cancer patients due to wasting syndrome (cachexia), which is a characteristic feature of many malignancies, and its incidence is between 16 and $75 \% .{ }^{11-12}$. The gold standard method recommended by international working groups for the detection of sarcopenia is computed tomography (CT $)^{13-14}$. The Skeletal muscle index (SMI) is a semiquantitative parameter which is calculated by dividing the muscle area given by CT with the square of the patient's height. Sexspecific SMI cut-offs are used to diagnose sarcopenia ${ }^{13,15}$.

There are numerous studies reporting the impact of CT-determined sarcopenia in various cancers ${ }^{6,15-19}$. Presence of CT-determined sarcopenia in cancer patients increases perioperative comorbidity such as a higher risk of postoperative infections, longer hospitalization periods and high hospital costs s, $15,20-23$. Sarcopenia can also cause early termination of neoadjuvant chemotherapy because of dose-limiting effect $^{24-25}$.

Additionally, sarcopenic patients show significantly worse survival than non-sarcopenic patients ${ }^{6,15-19}$. Presence of sarcopenia statistically reduces both DFS and OS in patients undergoing curative radical gastric surgery ${ }^{7-8}$ and predicts survival in patients with advanced gastric cancer ${ }^{26}$.

Data about effects of sarcopenia on DFS and OS reported from Europe is more limited than eastern Asia and there is not any study on this subject in Turkish population. In this study,we aimed to evaluate the effect of CT- dedected sarcopenia on prognosis in gastric cancer patients.

\section{Materials And Methods}

\section{Patient selection}

This study is approved by the local Institutional Review Board and conducted in accordance with Helsinki declaration. The medical records of patients with gastric adenocarcinoma who were admitted to the medical oncology department of Izmir Katip Celebi University Faculty of Medicine Ataturk Training and Research Hospital between 2008 and 2020 were retrospectively reviewed. Among these patients, those 
with CT examination at the time of diagnosis were included. The clinical and histopathological features of all patients, including sex, age, body mass index (BMI), serum albumin level, Eastern cooperative oncology group performance status (ECOG PS), survival outcomes were recorded. Patients with severe chronic inflammatory or autoimmune disease, having steroid treatment and having severe comorbidity were excluded.

\section{Definition of CT-Based Sarcopenia}

Computed tomography scans which were performed for staging at the time of diagnosis were used. A transverse abdominal CT image passing through the L3 vertebra level was transferred to an open access software program (sliceOmatic 5.0 visual c 14.0 update 3 ) available at https://coreslicer.com, and paravertebral and abdominal wall muscle areas (cm2) was measured. Skeletal muscle index (SMI, $\left.\mathrm{cm}^{2} / \mathrm{m}^{2}\right)$ was determined by dividing of SMA $\left(\mathrm{cm}^{2}\right)$ to the square of the patient's height $\left(\mathrm{m}^{2}\right)$. van der Werf's cutoff values were used ${ }^{13}$ and sarcopenia was defined as a SMI of $<41.6 \mathrm{~cm}^{2} / \mathrm{m}^{2}$ for men and $<$ $32 \mathrm{~cm}^{2} / \mathrm{m}^{2}$ for women.

\section{Evaluation of histopathological and clinical features}

The TNM staging was performed according to the American Joint Committee on Cancer (AJCC 2018) classification and coded as binary variables metastatic or non-metastatic ${ }^{5,26}$. Histological grade (well/moderate/ vs high), nodal status (N0 vs N1-3), tumor invasion dept (T1-2 vs T3-4), surgical resection margin (R0 vs R1-2), lymphadenectomy type (D1 vs D 2-3), lymphovascular invasion (negative vs positive), perineural invasion (negative vs positive), serum albumin level (low: $<3.5$ vs high: $\geq 3.5$ $\mathrm{mg} / \mathrm{dL}$ ), Eastern cooperative oncology group performance status (0-1 vs 2-4), age (young: $<60$ vs old: $\geq 60$ ) were recorded. Body mass index was calculated by dividing the patient's weight by the square of height $\left(\mathrm{kg} / \mathrm{m}^{2}\right)^{27}$. The patients were categorized according to $\mathrm{BMI}$ as follows: $\mathrm{BMl}>30 \mathrm{~kg} / \mathrm{m}^{2}$ : obese; 25.0-29.9 kg/m²: overweight; $20.0-24.9 \mathrm{~kg} / \mathrm{m}^{2}$ : normal weight; $<20.0 \mathrm{~kg} / \mathrm{m}^{2}$ : underweight.

\section{Treatment endpoints}

Disease free survival (DFS) was defined as the time from randomization (pathological diagnosis) to the first event of either recurrent disease or death.

Overall Survival (OS) was defined as the time from randomization (pathological diagnosis) to death from any cause or the final follow-up visit.

\section{Statistical analyses}

Statistical analyses were made by using the Statistical Package of Social Science (SPSS) version 16.0 software (Chicago, IL). The Kaplan-Meier method was performed to estimate survival outcomes and groups were compared by the log-rank test. Cox proportional hazards models were fit to determine the association between sarcopenia with survival outcomes after adjustment for patient and disease characteristics. The $95 \%$ confidence interval $(\mathrm{Cl})$ was used to quantify the relationship between survival 
time and each independent factor and all statistical tests were carried out two-sided and a P value $\leq 0.05$ was considered statistically significant.

\section{Results}

Four hundred eighty GC patients were found and 226 of them who met the inclusion criteria were included. Of the patients, 154 (68.1\%) were men and 72 (31.9\%) were women and median age was 62 years (range 17-85). 141 patients (62.4\%) presented at non-metastatic and 85 (37.6\%) patients presented at metastatic stages. The clinicopathological features of the patients are listed in Table 1. 
Table 1

Clinicopathological characteristics of patients.

\begin{tabular}{|c|c|c|}
\hline Characteristics & Number of patients & $\%$ \\
\hline \multicolumn{3}{|l|}{ Age } \\
\hline Age $<60$ years & 101 & 44.7 \\
\hline Age $\geq 60$ years & 125 & 55.3 \\
\hline \multicolumn{3}{|l|}{ Sex } \\
\hline Male & 154 & 68.1 \\
\hline female & 72 & 31.9 \\
\hline \multicolumn{3}{|l|}{ ECOG PS } \\
\hline 0 & 113 & 50 \\
\hline 1 & 80 & 35.4 \\
\hline 2 & 12 & 5.3 \\
\hline 3 & 21 & 9.3 \\
\hline \multicolumn{3}{|l|}{ BMI } \\
\hline$<20$ & 41 & 18.1 \\
\hline $20-24.9$ & 78 & 34.5 \\
\hline $25-29.9$ & 75 & 33.2 \\
\hline$>30$ & 32 & 14.2 \\
\hline \multicolumn{3}{|l|}{ sarcopenia } \\
\hline Non- sarcopenia & 151 & 66.8 \\
\hline sarcopenia & 75 & 33.2 \\
\hline \multicolumn{3}{|l|}{ Albumın } \\
\hline$\geq 3.5$ & 152 & 67.3 \\
\hline$<3.5$ & 74 & 32.7 \\
\hline \multicolumn{3}{|l|}{ Nuclear grade } \\
\hline Grade 1-2 & 80 & 35.4 \\
\hline Grade 3 & 75 & 33.2 \\
\hline
\end{tabular}

ECOG PS: Eastern cooperative Oncology Group (ECOG) Performance Status BMI:Body Mass Index 


\begin{tabular}{|c|c|c|}
\hline Characteristics & Number of patients & $\%$ \\
\hline Negative & 42 & 18.6 \\
\hline Positive & 86 & 38.1 \\
\hline \multicolumn{3}{|l|}{ Perıneural ınvasion } \\
\hline Negative & 42 & 18.6 \\
\hline Positive & 82 & 36.3 \\
\hline \multicolumn{3}{|l|}{ Tumor invasıon dept } \\
\hline T1 & 17 & 7.5 \\
\hline T2 & 16 & 7.1 \\
\hline T3 & 64 & 28.3 \\
\hline T4 & 49 & 21.7 \\
\hline \multicolumn{3}{|l|}{ Lymph node metastasis } \\
\hline NO & 38 & 16.8 \\
\hline N1 & 21 & 9.3 \\
\hline N2 & 36 & 15.9 \\
\hline N3 & 51 & 22.6 \\
\hline \multicolumn{3}{|l|}{ surgical resection margin } \\
\hline Ro & 110 & 48.7 \\
\hline R1-2 & 36 & 15.9 \\
\hline Lymphadenectomy type & 86 & 60.1 \\
\hline D1 & 54 & 37.8 \\
\hline D2 & 3 & 2.1 \\
\hline \multicolumn{3}{|l|}{ D3 } \\
\hline \multicolumn{3}{|l|}{ Stage } \\
\hline 1 & 21 & 9.3 \\
\hline 2 & 19 & 8.4 \\
\hline 3 & 101 & 44.7 \\
\hline 4 & 85 & 37.6 \\
\hline
\end{tabular}




\begin{tabular}{|lcc|}
\hline Characteristics & Number of patients & $\%$ \\
\hline Exitus & & \\
\hline No & 63 & 27.9 \\
\hline Yes & 163 & 72.1 \\
\hline ECOG PS: Eastern cooperative Oncology Group (ECOG) Performance Status BMl:Body Mass Index \\
\hline
\end{tabular}

Seventy-five patients (33.2\%) were sarcopenic. Among them, 18.1\% were categorized as underweight and $14.2 \%$ as obese. The sarcopenic patients tended to be older $(p<0.001)$, men $(p=0.001)$, at metastatic stage $(p<0.001)$, have lower BMI $(p=0.023)$ and have lower ECOG PS $(p<0.001)$ compared with nonsarcopenic patients (Table 2). The prevalence of sarcopenia was $20.6 \%(n: 22 ; p<0.0001)$ in patients with $\mathrm{BMI} \geq 25$ and was $15.6 \%(n: 5 ; p=0.023)$ in patients with $B M I \geq 30$. The sarcopenia prevalence was $47.2 \%$ $(n: 59)$ in patients older than 60 years, while it was $15.8 \%(n: 16)$ in younger patients $(p<0.0001)$. 
Table 2

Clinical characteristics of the patients with gastric cancer by sarcopenic status

\begin{tabular}{|c|c|c|c|}
\hline & No sarcopenia, n (\%) & Sarcopenia, n (\%) & $\mathrm{p}$ value \\
\hline Gender & $92(59.7 \%)$ & $62(40.3 \%)$ & 0.001 \\
\hline Men & 59 (81.9\%) & 13 (18.1\%) & \\
\hline \multicolumn{4}{|l|}{ Women } \\
\hline BMI status, & $124(63.9)$ & $70(36.1)$ & 0.023 \\
\hline$<30$ & $27(84.4)$ & $5(15.6)$ & \\
\hline \multicolumn{4}{|l|}{$\geq 30$} \\
\hline Age & $85(84.2)$ & $16(15.8)$ & $<0.001$ \\
\hline$<60$ & $66(52.8)$ & $59(47.2)$ & \\
\hline \multicolumn{4}{|l|}{$\geq 60$} \\
\hline Metastatic status & $107(75.9)$ & $34(24.1)$ & $<0.001$ \\
\hline No & $44(51.8)$ & $41(48.2)$ & \\
\hline \multicolumn{4}{|l|}{ Yes } \\
\hline ECOG status & $138(71.1)$ & $56(28.9)$ & 0.001 \\
\hline$<2$ & $13(40.8)$ & 19 (59.4) & \\
\hline \multicolumn{4}{|l|}{$\geq 2$} \\
\hline Albumine level & $49(66.2)$ & 25(33.8) & 0.505 \\
\hline$<3.5$ & $102(67.1)$ & $50(32.9)$ & \\
\hline$\geq 3.5$ & & & \\
\hline
\end{tabular}

The median DFS was 27 months $(95 \% \mathrm{Cl}, 1.5-52.4)$ in patients with sarcopenia and non-appliceable in patients without sarcopenia in patients undergoing curative surgery for gastric cancer $(p=0.041)$ (Figure.1). The median OS was 10 months $(95 \% \mathrm{Cl}, 7.7-12.2)$ in patients with sarcopenia and 29 months $(95 \% \mathrm{Cl}, 21.3-36.6)$ in patients without sarcopenia $(\mathrm{p}<0.0001)$ (Figure 2$)$.

In the univariate Cox regression model, high nuclear grade, lymphovascular invasion, perineural invasion, tumor invasion depth, lymph node metastasis, resection margin, stage, and presence of sarcopenia were associated with shorter DFS; age, ECOG PS, grade, lymphovascular invasion, perineural invasion, tumor invasion depth, lymph node metastasis, resection margin, stage and presence of sarcopenia were statistically associated with shorter OS (all, p<0.05 (Supplementary Table1). 
In the multivariate Cox regression model, presence of sarcopenia $(B=0.850 ; p=0.024)$, lymphovascular invasion $(B=1.941 ; p=0.002)$ and positive surgical resection margin $(B=1.092 ; p=0.002)$ were statistically significant predictors for DFS (Table 3$)$. Presence of sarcopenia $(B=0.988 ; p=0.001)$, lymphovascular invasion $(B=0.904 ; p=0.018)$, positive surgical resection margin $(B=0.996 ; p=0.001)$ and tumor stage $(B=1.006 ; p=0.026)$ were statistically significant predictors for OS (Table 4).

Table 3

Univariate analysis of factors associated with disease free survival and Cox proportional hazards regression model of clinical factors predicting disease free survival in patients with gastric cancer

\begin{tabular}{|lllll|}
\hline & $\begin{array}{l}\text { Log Rank (Mantel } \\
\text { Cox) }\end{array}$ & & $\begin{array}{l}\text { Cox-proportional } \\
\text { Hazard }\end{array}$ & \\
\hline & Chi-square & $p$ & $B(95 \%$ Cl) & $p$ \\
\hline $\begin{array}{l}\text { Sarcopenia } \\
\text { (non-sarcopenia vs. } \\
\text { sarcopenia) }\end{array}$ & 4.44 & 0.035 & $0.850(1.11-4.89)$ & 0.024 \\
\hline $\begin{array}{l}\text { Lymphovascular invasion } \\
\text { (negative vs.positive) }\end{array}$ & 15.7 & & & 0.002 \\
\hline $\begin{array}{l}\text { Surgical resection margin } \\
\text { (R0 vs R1-2) }\end{array}$ & 9.06 & 0.000 & $1.941(2.08-23.23)$ & \\
\hline
\end{tabular}

Table 4

Univariate analysis of factors associated with overall survival and Cox proportional hazards regression model of clinical factors predicting overall survival in patients with gastric cancer

\begin{tabular}{|lllll|}
\hline & $\begin{array}{l}\text { Log Rank (Mantel } \\
\text { Cox) }\end{array}$ & \multicolumn{3}{l|}{$\begin{array}{l}\text { Cox-proportional } \\
\text { Hazard }\end{array}$} \\
\hline & Chi-square & $p$ & $B(95 \%$ Cl) & $p$ \\
\hline $\begin{array}{l}\text { Sarcopenia } \\
\text { (non-sarcopenia vs. sarcopenia) }\end{array}$ & 9.549 & 0.002 & $0.988(1.49-4.81)$ & 0.001 \\
\hline $\begin{array}{l}\text { Lymphovascular invasion } \\
\text { (negative vs.positive) }\end{array}$ & 6.546 & 0.011 & $0.904(1.17-5.20)$ & 0.018 \\
\hline $\begin{array}{l}\text { Surgical resection margin } \\
\text { (R0 vs R1-2) }\end{array}$ & 10.237 & 0.001 & $0.996(1.51-4.84)$ & 0.001 \\
\hline $\begin{array}{l}\text { Tumor stage (non-metastatic vs. } \\
\text { metastatic) }\end{array}$ & 3.962 & & & 0.026 \\
\hline
\end{tabular}

\section{Discussion}


In this study, we analyzed the CT-determined sarcopenia retrospectively in gastric cancer patients. Male gender, advanced age, lower BMI, metastatic stage and lower ECOG PS were significantly related to sarcopenia. CT determined sarcopenia was independently associated with a worse DFS and OS.

Frailty is a condition of increased vulnerability to poor resolution of homoeostasis after a stressor event, resulting in an increased risk of developing adverse health outcomes ${ }^{28}$. Although the definition of frailty is controversial and its assessment is subjective, in various studies, sarcopenia has been defined as an accurate and objective measure of frailty ${ }^{28-29}$. It is important to identify and assess sarcopenia at the time of diagnosis. The detection of an optimal sarcopenia cut-off value on CT imaging depends on the type of disease and patient factors like sex, age, and race ${ }^{30}$. Zhuang et al. used SMI cut-offs to define sarcopenia (L3 muscle area: men, $40.8 \mathrm{~cm}^{2} / \mathrm{m}^{2}$; women, $34.9 \mathrm{~cm}^{2} / \mathrm{m}^{2}$ ), while Nishigori et al. reported cut-off values for skeletal muscle mass impacting on OS of patients with advanced gastric cancer as 53 $\mathrm{cm}^{2} / \mathrm{m}^{2}$ in men and $41 \mathrm{~cm}^{2} / \mathrm{m}^{2}$ in women ${ }^{20,7,39}$. We used the cut-off values of a European Werf's study ${ }^{13}$ as we thought it would be more suitable for the anthropometric structure of the Turkish people. Amoung the our patients, 75 (33.2\%) of them were sarcopenic. Tegels et al. found the sarcopenia ratio of $57.7 \%$ in the patients undergoing surgery for gastric cancer ${ }^{12}$. They used the cut-off values of American patients and the cut-off values were higher than the European study of Werf's and we think it explains the high prevalence of sarcopenia in their series ${ }^{12}$.

The prevalence of sarcopenia also depends on the type and stage of cancer, the gender, age, $\mathrm{BMI}$ and the ECOG PS of the patient ${ }^{7,11,30-33}$. Haiducu et al. evaluated the prevalence of sarcopenia in digestive cancers and they reported the highest prevalence of sarcopenic patients was in esophageal (70.4\%) and hepatic $(60.3 \%)$ cancers, following by biliary tract $(49.3 \%)$, pancreatic $(45.70 \%)$ and gastric cancer $(32.05 \%)^{31}$. The prevalence of sarcopenia is higher in patients with locally advanced disease compared to patients with early-stage disease ${ }^{32,34}$. In our study, while the prevalence of sarcopenia was $24 \%$ in the group with non-metastatic disease, this rate was found to be $42.2 \%$ in the group with metastatic disease. This is because tumors that have progressed from local disease to metastatic stage may also produce more cancer-related cytokines, more oral intake disturbance due to the local effect of the tumor that may induce sarcopenia ${ }^{33}$. Hong-Bo Zou found the sarcopenia ratio as $20.0 \%$ in non-metastatic stage gastric cancer patients ${ }^{32}$.

We found a higher prevalance of sarcopenia in men (40.3\%) than women (18.1\%). Fukuda et al. reported that the prevalance of men in the sarcopenic group was higher than in the non-sarcopenic group in elderly gastric cancer patients undergoing gastrectomy $(28.7 \% \text { vs. } 6.06 \% ; p=0.009)^{35}$. In another study including 276 newly diagnosed cancer patients, the prevalence of sarcopenia in men was found to be statistically higher than in women $(25.4 \% \text { vs } 5,9 \% \text {.; } p<0.0001)^{36}$. Our results were also similar to the literature data.

Another common indicator of a patient's general condition is BMI. We found that sarcopenia prevalence was lower in obese group (15.6\%) compared to non-obese group (36.1\%). Zhuang et al. reported that 
sarcopenia was negatively correlated with lower BMI in patients undergoing radical gastrectomy for $\mathrm{GC}^{7}$. Similarly, Oflazoglu et al. reported the prevalence of sarcopenia was lower in obese and overweight patients compared to normal and underweight ones with newly diagnosed cancer ${ }^{11}$.

In this study the prevalence of sarcopenia was found to be lower in the group with good ECOG status (28.9\% in ECOG PS 0-1) than the worse one (59.4\% in ECOG PS 2-3). Similarly, Prado et al. investigated the prevalence of sarcopenia in patients with solid tumors of the respiratory and gastrointestinal tract and they found lower ratios in patients with good functional scores (ECOG PS 0-1) compared to patients with poor functional scores (ECOG PS2-3) $(47 \% \text { vs } 53 \% \text {, respectively } P=0.009)^{30}$. A similar result was observed in the study of Oflazoğlu et al. While the rate of sarcopenia was $14.3 \%$ in patients with ECOG PS 0 , the rate of sarcopenia was significantly higher at $23 \%$ in patients with ECOG PS 1-2 $(p=0.026)^{11}$. Oflazoglu et al. hypothesized that the reason for the higher prevalence of sarcopenia in the group of patients with low performance scores might be because of less physical activity and less food intake, which eventually caused loss of muscle mass ${ }^{11}$.

In the present study, sarcopenia prevalence was higher in patients over 60 years (47.2\%) than those under 60 years $(15.8 \%)$. It has been shown in previous studies that the prevalence of sarcopenia increases with aging $^{11,20,32,34}$. The possible reasons for the accelerated loss of muscle mass in elderly people, can be the higher prevalance of chronic diseases, aging, drug usage and more sedentary lifestyle.

Many reports have suggested that sarcopenia was associated with both short and long-term survival outcomes $7,8,15,20,37,39$, but in fewer studies no significant relation was found between sarcopenia and short ${ }^{12,34,38}$ or long-term outcomes in $\mathrm{GC}^{12,24}$. In both univariate and multivariate analyses we found that the sarcopenic patients have poor DFS and OS. Zhuang et al. evaluated the effect of sarcopenia on shortterm and long-term survival outcomes after radical gastrectomy using preoperative abdominal CT scanning ${ }^{7}$. Patients with sarcopenia had worse both $\mathrm{OS}_{\text {and }} \mathrm{DFS}^{7}$. Kudou et al. evaluated the prognostic significance of sarcopenia in patients with esophagogastric junction cancer or upper GC and they showed that sarcopenia was reducing both short-term and long-term survival outcomes ${ }^{8}$. Our findings were similar with their results. In O'Brien's study, which included 56 patients who underwent resection for gastric adenocarcinoma, no statistically significant difference was observed in recurrence-free survival (RFS) which defined as the length of time from the date of first therapy to the date of detection of tumor recurrence, death, or loss to follow-up of sarcopenic patients, while there was a statistically significant difference in OS with reduced survival ${ }^{38}$. A study by Nishigori et al. demonstrated that sarcopenia was an independent predictor of DFS $(p=0.035)$ and OS $(p=0.005)$ in the 177 eligible patients with advanced $\mathrm{GC}^{39}$. Hong-Bo Zou found that three-year OS was $66.1 \%$ in sarcopenia group and $80.6 \%$ in nonsarcopenia group in the operated gastric cancer $(p=0.014)^{32}$. Lee at al. reported shorter OS (median, 6.8 months) in sarcopenic patients than those non-sarcopenic ones (median 10.3 months) with advanced gastric cancer ${ }^{37}$. We found similar survival outcomes with the above mentioned study in the metastatic group (median, 7 months in sarcopenic vs. 14 months in non-sarcopenic groups). 
However, Tegels et al. did not find a significant correlation between sarcopenia and short or long term survival in patients undergoing surgery for $\mathrm{GC}^{12}$. This may be due to the cut-off values used for the definition of sarcopenia and the demographic and clinical characteristics of the patients ${ }^{12}$. Another study by Kuwada et al. evaluated sarcopenic and non-sarcopenic short-term and long-term survivals in 491 gastrectomy patients ${ }^{34}$. While sarcopenia did not contribute significantly to short-term outcomes, sarcopenic patients had significantly worse survival ${ }^{34}$. The cutoff values used to define sarcopenia were 69.7 and $54.2 \mathrm{~cm} 2 / \mathrm{m} 2$ for men and women, respectively. This may have affected the short-term results. Palmela at al. found that sarcopenia was not associated with poor survival in patients with locally advanced gastric cancer ${ }^{24}$. The higher rate of sarcopenic obese patients in this study, as well as the low overall number of patients at 48 , may explain the relative survival relationship of sarcopenia.

Our study has several limitations. First, only 226 of the 480 total patients screened were included because they met the available abdominal CT data or inclusion criteria at baseline. This may have led to selection bias. Second, this is a retrospective, single-center study; therefore, there may be bias in the population and the results of this study need to be validated in future by multicenter prospective studies. To improve the comparability of studies, it is important to standardize the definition of CT-assessed sarcopenia and outcome-related thresholds adjusted for tumor type, age, sex and ethnicity.

In conclusion, CT determined sarcopenia is a significant predictor of poor clinical outcome s in gastric cancer. Each gastric cancer patient should also be evaluated in terms of sarcopenia besides clinical, radiologic and histopatologic examination.

\section{Declarations}

Conflict of interest: The authors declare that they have no conflict of interest.

Author contributions Study concept: Y. Yildiz and S. Karasu Study design: Y. Yildiz and S. Karasu Data acquisition:Y. Yildiz, S. Karasu, K. Cetinoglu, B. Dalkılınc, Y. Kucukzeybek, A. Alacacioglu, S. Unal, Z. Guc, B. Kucukzeybek, T. Salman. Quality control of data:Y. Yildiz, U. oflazoglu and S. Karasu. Data analysis and interpretation: Y. Yildiz and S. Karasu, U. Oflazoglu Statistical analysis: Y. Yildiz, U. Oflazoglu and A Alacacioglu. Manuscript preparation: Y. Yildiz and S. Karasu Manuscript editing:Y. Yildiz and S. Karasu . Manuscript review: Y. Yildiz and S. Karasu, U. oflazoglu and Y. Kücükzeybek

Ethical approval The study was approved by the Institutional Review Board at Izmir Katip Celebi University.

Funding: None

Code availability: None

Availability of data and material: Yes 
Consent to participate: None. Because it is a retrospective study

Consent for publication: None. Because it is a retrospective study

\section{References}

1. Bray F, Ferlay J, Soerjomataram I, Siegel RL, Torre LA, Jemal A (2018 Nov) Global cancer statistics 2018: GLOBOCAN estimates of incidence and mortality worldwide for 36 cancers in 185 countries. CA Cancer J Clin 68(6):394-424

2. Melina Arnold MJ, Rutherford A, Bardot J, Ferlay (2019 Nov) T Progress in cancer survival, mortality, and incidence in seven high-income countries 1995-2014 (ICBP SURVMARK-2): a population-based study Lancet Oncol. 20:1493-150511

3. Coburn N, Cosby R, Klein L, Knight G, Malthaner R, Mamazza J et al (2018 Feb) Staging and surgical approaches in gastric cancer: A systematic review. Cancer Treat Rev 63:104-115

4. Liang Y, Cui J, Cai Y, Liu L, Zhou J, Li Q et al (2019) "D2 plus" lymphadenectomy is associated with improved survival in distal gastric cancer with clinical serosa invasion: a propensity score analysis.Sci Rep. Dec 16;9(1)

5. Rohde H, Gebbensleben B, Bauer P, Stutzer H, Zieschang J (1989) Has there been any improvement in the staging of gastric cancer? Findings from the German Gastric Cancer TNM Study Group. Cancer 64:2465-2481

6. Xie H, Gong Y, Kuang J, Yan L, Ruan G, Tang S et al (2020 Jul) Computed Tomography-Determined Sarcopenia Is a Useful Imaging Biomarker for Predicting Postoperative Outcomes in Elderly Colorectal Cancer Patients. Cancer Res Treat 52(3):957-972

7. Zhuang CL, Huang DD, Pang WY, Zhou CJ, Wang SL, Lou N et al (2016 Mar) Sarcopenia is an Independent Predictor of Severe Postoperative Complications and Long-Term Survival After Radical Gastrectomy for Gastric Cancer: Analysis from a Large-Scale Cohort. Med (Baltim) 95(13):e3164

8. Kudou K, Saeki H, Nakashima Y, Edahiro K, Korehisa S, Taniguchi D et al (2017 Jul) Prognostic Significance of Sarcopenia in Patients with Esophagogastric Junction Cancer or Upper Gastric Cancer. Ann Surg Oncol 24(7):1804-1810

9. Rosenberg IH (1997 May) Sarcopenia: origins and clinical relevance. J Nutr 127(5 Suppl):990S$991 S$

10. Cruz-Jentoft AJ, Bahat G, Bauer J, Boirie Y, Bruyère O, Cederholm T et al (2019) Writing Group for the European Working Group on Sarcopenia in Older People 2 (EWGSOP2), and the Extended Group for EWGSOP2. Sarcopenia: revised European consensus on definition and diagnosis. Age Ageing. Jul 1;48(4):601

11. Oflazoglu U, Alacacioglu A, Varol U, Kucukzeybek Y, Salman T, Taskaynatan H et al (2020 Feb) Prevalence and related factors of sarcopenia in newly diagnosed cancer patients. Support Care Cancer 28(2):837-843 
12. Tegels JJ, van Vugt JL, Reisinger KW, Hulsewé KW, Hoofwijk AG, Derikx JP et al (2015 Sep) Sarcopenia is highly prevalent in patients undergoing surgery for gastric cancer but not associated with worse outcomes. J Surg Oncol 112(4):403-407

13. van der Werf A, Langius JAE, de van der Schueren MAE, Nurmohamed SA, van der Pant KAMI, Blauwhoff-Buskermolen S et al (2018 Feb) Percentiles for skeletal muscle index, area and radiation attenuation based on computed tomography imaging in a healthy Caucasian population. Eur $\mathrm{J}$ Clin Nutr 72(2):288-296

14. Cesari M, Fielding RA, Pahor M, Goodpaster B, Hellerstein M, van Kan GA et al (2012 Sep) International Working Group on Sarcopenia. Biomarkers of sarcopenia in clinical trialsrecommendations from the International Working Group on Sarcopenia. J Cachexia Sarcopenia Muscle 3(3):181-190

15. Kawamura T, Makuuchi R, Tokunaga M, Tanizawa Y, Bando E, Yasui H et al (2018 Jun) Long-Term Outcomes of Gastric Cancer Patients with Preoperative Sarcopenia. Ann Surg Oncol 25(6):16251632

16. Portal D, Hofstetter L, Eshed I, Dan-Lantsman C, Sella T, Urban D et al (2019) L3 skeletal muscle index (L3SMI) is a surrogate marker of sarcopenia and frailty in non-small cell lung cancer patients. Cancer Manag Res. Apr 1;11:2579-2588

17. Iritani S, Imai K, Takai K, Hanai T, Ideta T, Miyazaki T et al (2015 Mar) Skeletal muscle depletion is an independent prognostic factor for hepatocellular carcinoma. J Gastroenterol 50(3):323-332

18. Choi Y, Oh DY, Kim TY, Lee KH, Han SW, Im SA et al (2015) Skeletal muscle depletion predicts the prognosis of patients with advanced pancreatic cancer undergoing palliative chemotherapy, independent of body mass index. PLoS ONE 10(10):e0139749

19. Harada K, Ida S, Baba Y, Ishimoto T, Kosumi K, Tokunaga R et al (2016 Aug) Prognostic and clinical impact of sarcopenia in esophageal squamous cell carcinoma. Dis Esophagus 29(6):627-633

20. Wang SL, Zhuang CL, Huang DD, Pang WY, Lou N, Chen FF et al (2016 Feb) Sarcopenia Adversely Impacts Postoperative Clinical Outcomes Following Gastrectomy in Patients with Gastric Cancer: A Prospective Study. Ann Surg Oncol 23(2):556-564

21. Simonsen C, de Heer P, Bjerre ED, Suetta C, Hojman P, Pedersen BK et al (2018 Jul) Sarcopenia and Postoperative Complication Risk in Gastrointestinal Surgical Oncology: A Meta-analysis. Ann Surg 268(1):58-69

22. Tamura T, Sakurai K, Nambara M, Miki Y, Toyokawa T, Kubo N, ET AL (2019 Feb) Adverse Effects of Preoperative Sarcopenia on Postoperative Complications of Patients With Gastric Cancer. Anticancer Res 39(2):987-992

23. Chen FF, Zhang FY, Zhou XY, Shen X, Yu Z, Zhuang CL (2016 Sep) Role of frailty and nutritional status in predicting complications following total gastrectomy with D2 lymphadenectomy in patients with gastric cancer: a prospective study. Langenbecks Arch Surg 401(6):813-822

24. Palmela C, Velho S, Agostinho L, Branco F, Santos M, Santos MP et al (2017 Mar) Body Composition as a Prognostic Factor of Neoadjuvant Chemotherapy Toxicity and Outcome in Patients with Locally 
Advanced Gastric Cancer. J Gastric Cancer 17(1):74-87

25. Tan BH, Brammer K, Randhawa N, Welch NT, Parsons SL, James EJ, Catton JA (2015 Mar) Sarcopenia is associated with toxicity in patients undergoing neo-adjuvant chemotherapy for oesophago-gastric cancer. Eur J Surg Oncol 41(3):333-338

26. Tegels JJ, de Maat MF, Hulsewé KW, Hoofwijk AG, Stoot JH (2014 Mar) Value of geriatric frailty and nutritional status assessment in predicting postoperative mortality in gastric cancer surgery. J Gastrointest Surg 18(3):439-445. discussion 445-6.

27. Iannuzzi-Sucich M, Prestwood KM, Kenny AM (2002 Dec) Prevalence of sarcopenia and predictors of skeletal muscle mass in healthy, older men and women. J Gerontol A Biol Sci Med Sci 57(12):M772M777

28. Reisinger KW, van Vugt JL, Tegels JJ, Snijders C, Hulsewé KW, Hoofwijk AG et al (2015 Feb) Functional compromise reflected by sarcopenia, frailty, and nutritional depletion predicts adverse postoperative outcome after colorectal cancer surgery. Ann Surg 261(2):345-352

29. Buettner S, Wagner D, Kim Y, Margonis GA, Makary MA, Wilson A et al (2016) Inclusion of Sarcopenia Outperforms the Modified Frailty Index in Predicting 1-Year Mortality among 1,326 Patients Undergoing Gastrointestinal Surgery for a Malignant Indication. J Am Coll Surg. Apr;222(4):397407.e2

30. Sakurai K, Kubo N, Tamura T, Toyokawa T, Amano R, Tanaka H et al (2017 Sep) Adverse Effects of Low Preoperative Skeletal Muscle Mass in Patients Undergoing Gastrectomy for Gastric Cancer. Ann Surg Oncol 24(9):2712-2719

31. Haiducu C, Buzea A, Mirea LE, Dan GA (2021 Nov) The prevalence and the impact of sarcopenia in digestive cancers. A systematic review. Rom J Intern Med 20;59((4):328-344

32. Zou HB, Yan XL, Dong WX, Yu DY, Zhang FM, Zhou LP et al (2021 Aug) Sarcopenia is a predictive factor of poor quality of life and prognosis in patients after radical gastrectomy. Eur J Surg Oncol 47(8):1976-1984

33. Borggreve AS, den Boer RB, van Boxel GI, de Jong PA, Veldhuis WB, Steenhagen E et al (2020) The Predictive Value of Low Muscle Mass as Measured on CT Scans for Postoperative Complications and Mortality in Gastric Cancer Patients: A Systematic Review and Meta-Analysis. J Clin Med. Jan $11 ; 9(1): 199$

34. Kuwada K, Kuroda S, Kikuchi S, Yoshida R, Nishizaki M, Kagawa S et al (2018 May) Sarcopenia and Comorbidity in Gastric Cancer Surgery as a Useful Combined Factor to Predict Eventual Death from Other Causes. Ann Surg Oncol 25(5):1160-1166

35. Fukuda Y, Yamamoto K, Hirao M, Nishikawa K, Nagatsuma Y, Nakayama T et al (2016 Jul) Sarcopenia is associated with severe postoperative complications in elderly gastric cancer patients undergoing gastrectomy. Gastric Cancer 19(3):986-993

36. Oflazoglu U, Alacacioglu A, Varol U, Kucukzeybek Y, Salman T, Taskaynatan H et al (2020 Jun) Chemotherapy-induced sarcopenia in newly diagnosed cancer patients: Izmir Oncology Group (IZOG) study. Support Care Cancer 28(6):2899-2910 
37. Lee JS, Kim YS, Kim EY, Jin W (2018 Aug) Prognostic significance of CT-determined sarcopenia in patients with advanced gastric cancer.PLoS One. 20;13(8)

38. O'Brien S, Twomey M, Moloney F, Kavanagh RG, Carey BW, Power D et al (2018 Sep) Sarcopenia and Post-Operative Morbidity and Mortality in Patients with Gastric Cancer. J Gastric Cancer 18(3):242252

39. Nishigori T, Tsunoda S, Obama K, Hisamori S, Hashimoto K, Itatani Y et al (2018 Nov) Optimal Cutoff Values of Skeletal Muscle Index to Define Sarcopenia for Prediction of Survival in Patients with Advanced Gastric Cancer. Ann Surg Oncol 25(12):3596-3603

\section{Figures}

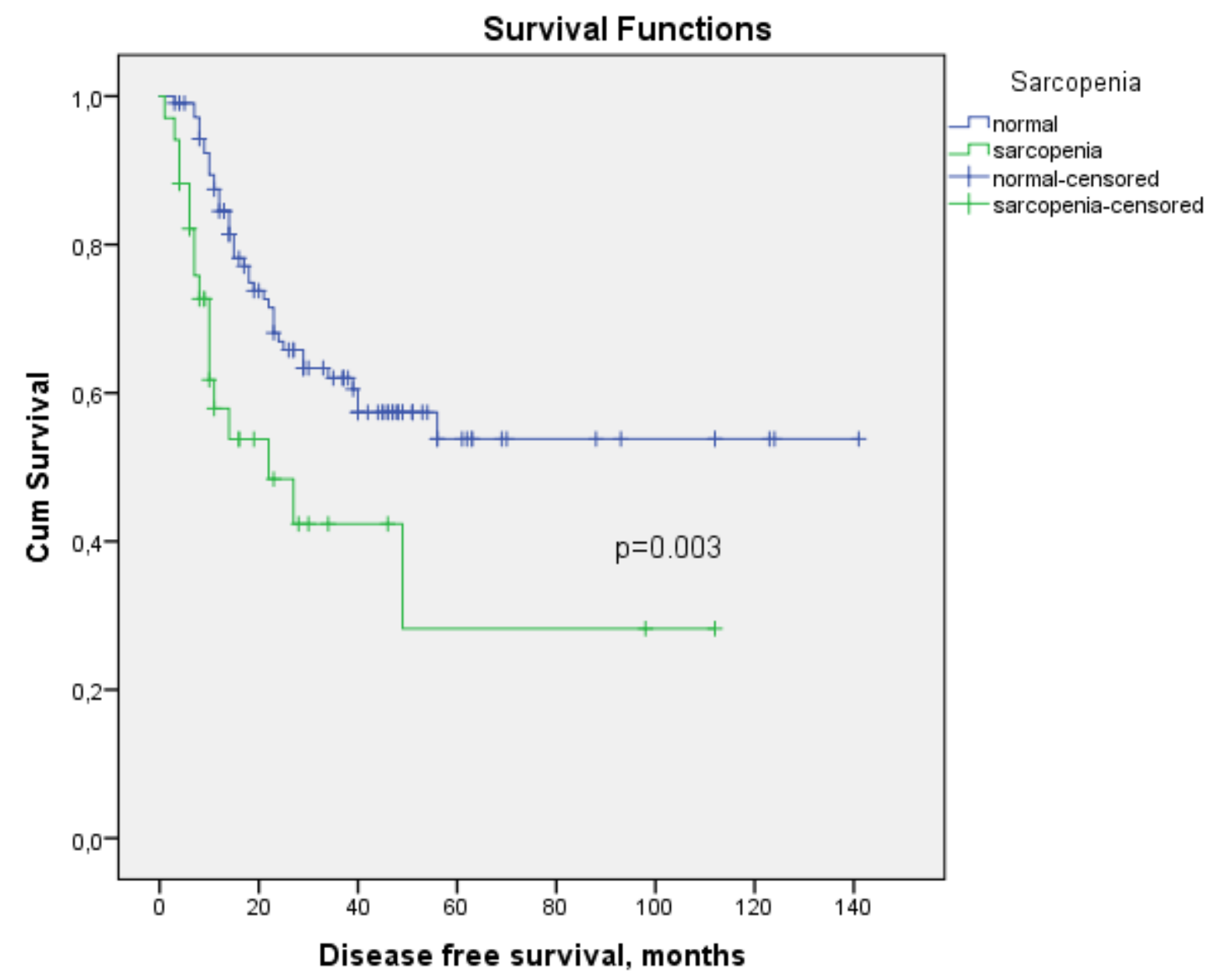

Figure 1

Caption not included with this version. 


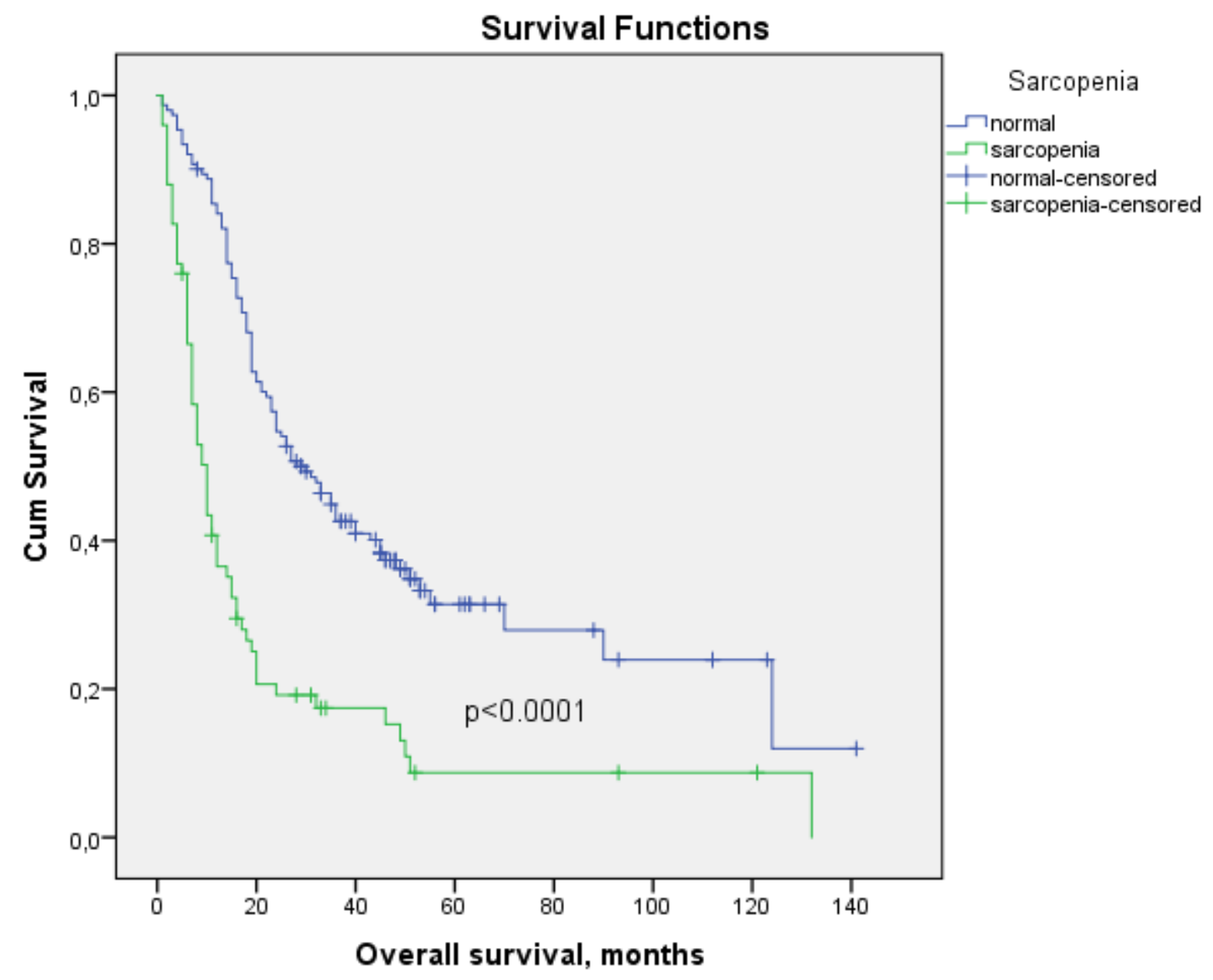

Figure 2

Caption not included with this version.

\section{Supplementary Files}

This is a list of supplementary files associated with this preprint. Click to download.

- SupplementaryTable1.docx 